
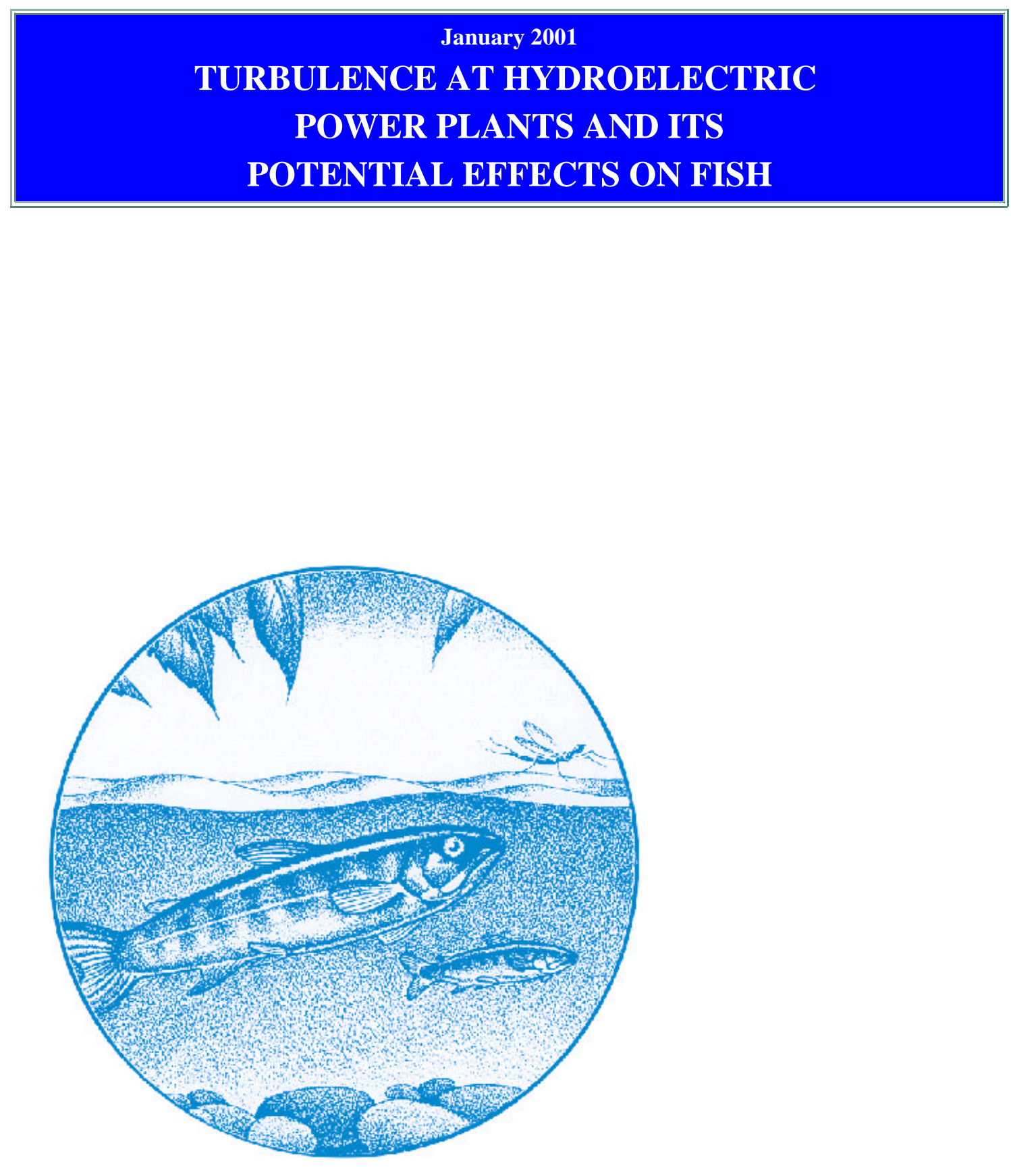

DOE/BP-26531-1 
This report was funded by the Bonneville Power Administration (BPA), U.S. Department of Energy, as part of BPA's program to protect, mitigate, and enhance fish and wildlife affected by the development and operation of hydroelectric facilities on the Columbia River and its tributaries. The views of this report are the author's and do not necessarily represent the views of BPA.

This document should be cited as follows:

Glenn F. Cada - Oak Ridge National Laboratory, Mufeed Odeh -U.S. Geological Survey-Biological Resources Division, Turbulence At Hydroelectric Power Plants And Its Potential Effects On Fish, Report to Bonneville Power

Administration, Contract No. 2000AI26531, Project No. 200005700, 37 electronic pages (BPA Report DOE/BP-26531-1)

This report and other BPA Fish and Wildlife Publications are available on the Internet at:

\section{http://www.efw.bpa.gov/cgi-bin/efw/FW/publications.cgi}

For other information on electronic documents or other printed media, contact or write to:

Bonneville Power Administration

Environment, Fish and Wildlife Division

P.O. Box 3621

905 N.E. 11th Avenue

Portland, OR 97208-3621

Please include title, author, and DOE/BP number in the request. 


\title{
TURBULENCE AT HYDROELECTRIC POWER PLANTS AND ITS POTENTIAL EFFECTS ON FISH
}

\author{
Prepared by: \\ Glenn F. Cada \\ Oak Ridge National Laboratory \\ P.O. Box 2008 \\ Oak Ridge, TN 37831-6036 \\ and \\ Mufeed Odeh \\ U.S. Geological Survey-Biological Resources Division \\ S.O. Conte Anadromous Fish Research Center \\ One Migratory Way \\ P.O. Box 796 \\ Turners Falls, MA 01376 \\ Prepared for: \\ U.S. Department of Energy \\ Bonneville Power Administration \\ Division of Fish and Wildlife \\ P.O. Box 3621 \\ Portland, OR 97208 \\ Project Number 2000-057-00 \\ Contract Number 00AI26531
}

January 2001 


\section{TABLE OF CONTENTS}

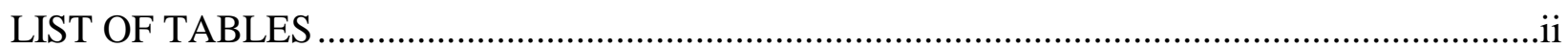

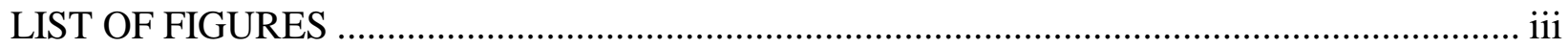

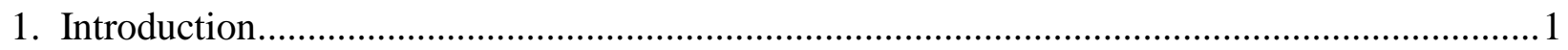

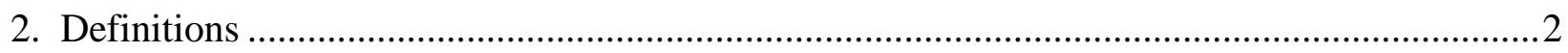

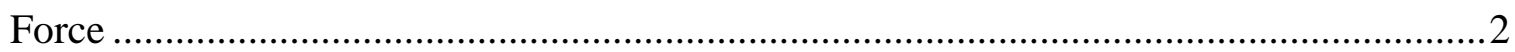

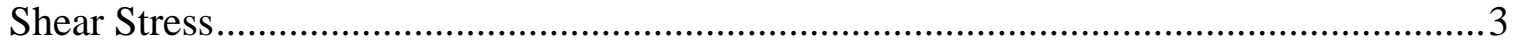

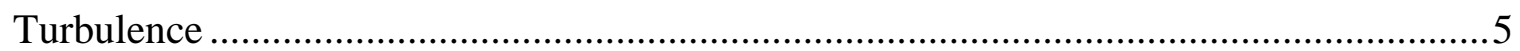

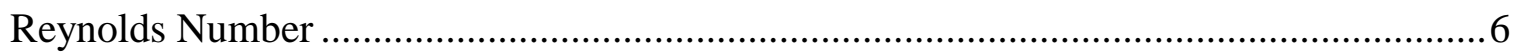

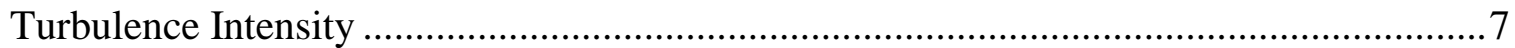

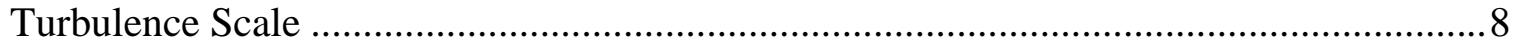

3. Shear and Turbulence in the Hydropower System........................................................ 11

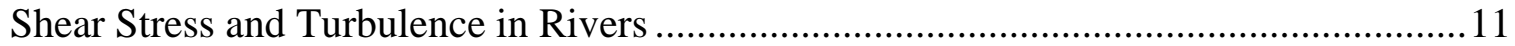

Shear Stress and Turbulence Associated with Ships .................................................... 13

Shear Stress and Turbulence at Hydroelectric Power Plants ........................................ 15

4. Experimental Studies Needed to Resolve the Turbulence Issue.........................................21

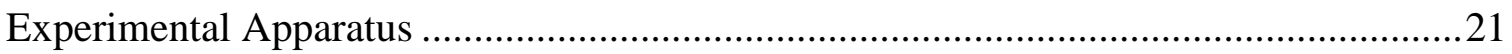

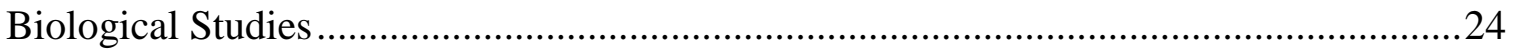

Treatment and Control Groups .........................................................24

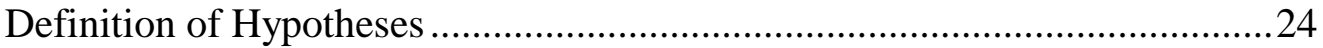

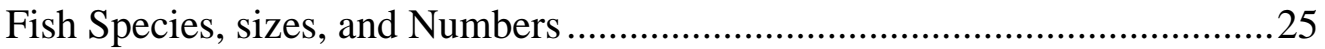

Holding Period and Observations .....................................................25

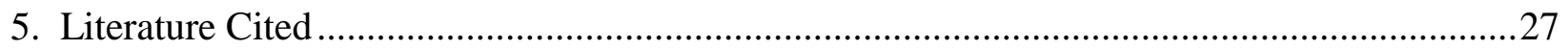




\section{LIST OF TABLES}

Table 1. Estimates of shear stress $\left(\mathrm{N} / \mathrm{m}^{2}\right)$ in natural and altered aquatic systems .....................11 


\section{LIST OF FIGURES}

Figure 1. Schematics showing the distortion due to shear forces in

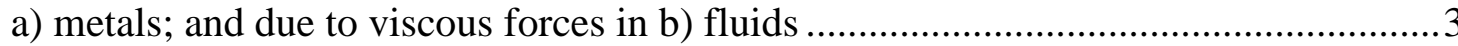

Figure 2. Turbulence scales compared to the size of a fish ...............................................

Figure 3. Eight Hazard Passage Zones associated with passage through a hydroelectric turbine. Source: Davidson (2000)

Figure 4. Schematic of the proposed turbulence chamber with the nozzles inlet option in place. The draft tube and propeller inserts can be used as other flow inlets 


\section{Introduction}

The fundamental influence of fluid dynamics on aquatic organisms is receiving increasing attention among aquatic ecologists. For example, the importance of turbulence to ocean plankton has long been a subject of investigation (Peters and Redondo 1997). More recently, studies have begun to emerge that explicitly consider the effects of shear and turbulence on freshwater invertebrates (Statzner et al. 1988; Hart et al. 1996) and fishes (Pavlov et al. 1994, 1995).

Hydraulic shear stress and turbulence are interdependent natural fluid phenomena that are important to fish, and consequently it is important to develop an understanding of how fish sense, react to, and perhaps utilize these phenomena under normal river flows. The appropriate reaction to turbulence may promote movement of migratory fish or prevent displacement of resident fish. It has been suggested that one of the adverse effects of flow regulation by hydroelectric projects is the reduction of normal turbulence, particularly in the headwaters of reservoirs, which can lead to disorientation and slowing of migration (Williams et al. 1996; Coutant et al. 1997; Coutant 1998). On the other hand, greatly elevated levels of shear and turbulence may be injurious to fish; injuries can range from removal of the mucous layer on the body surface to descaling to torn opercula, popped eyes, and decapitation (Neitzel et al. 2000a,b). Damaging levels of fluid stress can occur in a variety of circumstances in both natural and man-made environments.

This paper discusses the effects of shear stress and turbulence on fish, with an emphasis on potentially damaging levels in man-made environments. It defines these phenomena, describes studies that have been conducted to understand their effects, and identifies gaps in our knowledge. In particular, this report reviews the available information on the levels of turbulence that can occur within hydroelectric power plants, and the associated biological effects. The final section provides the preliminary design of an experimental apparatus that will be used to expose fish to representative levels of turbulence in the laboratory. 


\section{Definitions}

In this section we define terms and expressions of fluid and flow properties that are useful to understanding the hydrodynamic environment associated with hydroelectric power plants. Some of the mechanisms, such as turbulence, which the subject of this research project, and shear stress, are believed to be harmful to fish at high levels. It is important to understand the nature of these mechanisms and how they act on turbine- and spillway-passed fish. This will facilitate development of the appropriate biological response curves between the independent variable (velocity, energy, or force) and the dependent variable (fish disorientation, injury, or mortality). These mechanisms provide a link between fluid properties that can be measured or estimated in a test facility and possible biological effects that will be quantified.

\section{$\underline{\text { Force }}$}

Force, $F$, is defined as the rate of change of momentum with respect to time or the product of mass multiplied by acceleration, and is expressed in Newtons ( $\mathrm{N} \mathrm{or} \mathrm{kg} \cdot \mathrm{m} \cdot \mathrm{s}^{-2}$ ). For a fish striking a wall, the force would be the mass of the fish multiplied by the deceleration. A massive fish rapidly decelerating from $10 \mathrm{~m} / \mathrm{s}$ to $0 \mathrm{~m} / \mathrm{s}$ would experience more force hitting the wall than a small fish moving in the low-velocity boundary layer along the wall. This same relationship is true if, instead of a wall, the fish encounters another water mass of different velocity. Important factors that govern the effect of force are (1) size of the fish (larvae have lower mass than adults so they strike the wall/water mass with less force), (2) life stage (larvae are more sensitive to a given amount of force than adults), (3) the way in which the fish strikes the wall or water mass (whole side of the body vs. head-on). This last factor leads to a consideration of pressure. Pressure is force per unit area, applied perpendicular to the body surface, expressed in $\mathrm{N} / \mathrm{m}^{2}$. If all the force (fish's mass multiplied by acceleration) of striking the wall is focused on one small point (eyeball), there will be much greater pressure and injury than if the entire side of the fish's body strikes the wall. This is also true if, instead of a wall, the fish strikes another water mass of different velocity. The force associated with the different water mass could be distributed relatively uniformly over the whole body, or could be experienced as a pinpoint jet. The location and amount of the fish's body upon which the forces are focused have a bearing on the resultant damage. 


\section{$\underline{\text { Shear Stress }}$}

Force acting parallel, or tangential, to a surface is referred to as shearing force. When a tangential force (shearing force, $F_{\mathrm{V}}$ ) is applied to a solid, the cohesive forces between its molecules try to maintain its shape. As the shape of the solid changes, the cohesive forces increase; until the solid is permanently deformed, see Figure 1a. However, the cohesive forces resisting shear in a liquid are significant only when adjacent layers are moving at different velocities (Flammer et al. 1982). This is to say the rate of change of velocity, u, with respect to distance away from a boundary, y, is greater than zero (i.e. du/dy $\neq 0$ ), see Figure $1 \mathrm{~b}$. Shear stress in a liquid, therefore, depends greatly on its viscosity.

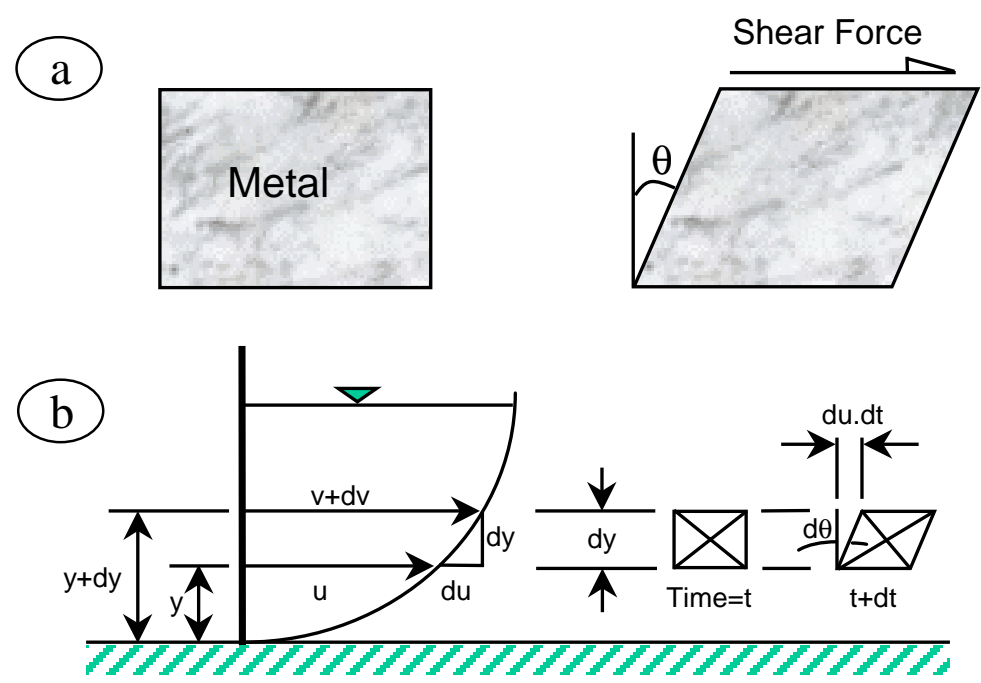

Rate of strain of a fluid element due to effects of viscosity

Figure 1. Schematics showing the distortion due to shear forces in a) metals; and due to viscous forces in b) fluids.

Viscosity, $\mu$, is a fluid property, which indicates the fluid's internal resistance to relative motion between its adjacent layers. This means that the shearing force, $F_{\mathrm{V}}$, is proportional to this rate of change of velocity of the flow with respect to the distance away from the boundary, (i.e. $\mathrm{F}_{\mathrm{V}} \propto \mathrm{du} / \mathrm{dy}$ ). The ratio du/dy is also called the rate of strain or rate of deformation of the fluid (Rouse 1946). Viscosity, $\mu$, is defined as the proportionality 
constant between shearing stress, $\tau$, (which is the shearing force divided by the area, i.e. $\tau=$ $\left.F_{\mathrm{V}} / \mathrm{A}\right)$ and the rate of strain of the fluid (or rate of deformation) (du/dy). This is to say, $\mu=$ $\left(F_{\mathrm{V}} / \mathrm{A}\right) /(\mathrm{du} / \mathrm{dy})$.

Therefore, by rearranging the terms, the shear stress, $\tau$, for viscous flows is defined as:

$$
\tau_{\text {laminar }}=\mu(\mathrm{du} / \mathrm{dy})
$$

It turns out that this relationship describes shear stresses in laminar flows, where viscous effects are substantial and the Reynolds' number, $\mathrm{R}_{\mathrm{e}}=\mathrm{u} \cdot \mathrm{d} / \mathrm{v}$, is equal to 1,500 or less (White 1992). In the formula for $R_{e}, u$ is velocity in $m / s, d$ is a characteristic length in $m$, and $v$ is the kinematic viscosity in $\mathrm{m}^{2} / \mathrm{s}$. In nature, fluid particles move and, therefore, deform in all directions. Hence, the fluid's rate of strain in a three-dimensional flow field can be expressed as $(d u / d y+d v / d x+d w / d z)$.

In most hydraulic systems, such as streams and hydropower systems, flows are turbulent (Nezu and Nakagawa 1993). The total shear stress is, therefore, affected by the instantaneous fluctuations in the flow field. Because turbulence and shear stress are interdependent a term describing the apparent viscosity of the flow (also called eddy viscosity, $\varepsilon$ ) is added to the dynamic viscosity, $\mu$, of the fluid to obtain the turbulent shear stress within the flow field. Therefore, for turbulent flows, Eq. (1) is modified to become:

$$
\tau_{\text {turbulent }}=(\mu+\varepsilon)(\mathrm{du} / \mathrm{dy})
$$

Unlike $\mu$, there are no tables that give values for $\varepsilon$. Eddy viscosity is dependent on how vigorous the turbulence is, and must be found by experimentation. However, because $\varepsilon$ is a function of the first and second derivatives of velocity (i.e., $\mathrm{dv} / \mathrm{dy}$ and $\mathrm{d}^{2} \mathrm{v} / \mathrm{dy}^{2}$ ), it can be calculated from the velocity profile. If the flow is entirely laminar, $\varepsilon$ is zero and Eq. 2 reduces to Eq. 1. For fully turbulent flow, effects due to dynamic viscosity are negligible $(\mu<<\varepsilon)$, and Eq. (2) reduces to:

$$
\tau_{\text {turbulent }}=\varepsilon(\mathrm{du} / \mathrm{dy})
$$


Shear stress is, therefore, a property that involves changes in water velocity $(u$, measured in $\mathrm{m} / \mathrm{s}$ ). Water velocity is important for transporting organisms or their food and for creating aquatic habitats. Uniform velocities in a stream or artificial conduit do not harm fish; a fish moving $0.2 \mathrm{~m} / \mathrm{s}$ or $20 \mathrm{~m} / \mathrm{s}$ will not be injured or disoriented if velocities of the water mass in which the fish is traveling are relatively uniform. However, when water velocities change on scales comparable to the size of a fish, damaging shear stresses can occur.

Shear stress occurs when two water (a viscous fluid) masses or layers of different velocities are adjacent to each other. As mentioned above, shear stress is directly proportional to the rate of change in water velocity over distance (rate of strain of the fluid). That is to say, if velocities of two adjacent water masses differed by $3 \mathrm{~m} / \mathrm{s}$ over a distance of $0.1 \mathrm{~m}$, the resultant rate of strain would be $30 \mathrm{~m} / \mathrm{s} / \mathrm{m}$. If water were a non-viscous fluid the fish would just spin freely in the flow field and would not experience any harm (other than maybe dizziness).

\section{Turbulence}

At high water velocities and because of edge effects and surface roughness of structures, given that water is a viscous fluid, flows in a hydropower turbine system are turbulent, rather than laminar. The tendency of water molecules to resist shear forces, due to the presence of viscosity, causes them to move irregularly. The shear stresses within a flow field tear the fluid into highly energetic, irregular, and three-dimensional eddies, with scales ranging from the size of the flow passage down to unity (Miller 1990). These eddies exist randomly in space and time in turbulent shear flows (Nezu and Nakagawa 1993). Turbulent flow occurs when fluid particles move in a highly irregular manner, even if the fluid as a whole is traveling in a single direction. That is, there are intense, small-scale motions present in directions other than that of the main, large-scale flow (Vogel 1994). Unlike laminar flow, which is most easily described by linear equations, turbulent flow can only be defined statistically (Gordon et al. 1992; Nezu and Nakagawa 1993); descriptions of the overall motion within turbulent flows cannot be taken as describing the paths of individual particles (Vogel 1994). 
Within a turbine system, natural river, or laboratory test apparatus, flows are so turbulent it would be difficult to separate the effects of normal forces (that cause pressure) from tangential forces (that cause shear stress), but rather the fluid stress will be a combination of the two. Also, the shear stresses are not uniformly applied to a fish; a fish encountering highvelocity water head-on is more likely to experience more shear stress on the head than on the tail. Also, resistance of a fish to shear stress may be size-specific; e.g., small rainbow trout may be less resistant than large rainbow trout. Resistance is certainly species-specific (eels are more resistant than shad) and probably life stage-specific (adults are more resistant than larvae; non-smolted chinook salmon juveniles are more resistant than chinook salmon smolts).

\section{Reynolds Number}

Forces acting on a flowing fluid include inertial, gravitational, viscous, and pressure, among others. Dynamic similitude in hydraulics uses mathematical expressions relating these forces, in a normalized form, to describe a physical process. The result of using dimensional analysis to describe a flow process produces meaningful dimensionless numbers, such as Reynolds and Froude numbers. Each of these numbers highlights the relative importance of the dominant force influencing that process (Rouse 1946). For example, the Froude number highlights the relative importance of gravitational forces in steady nonuniform flows, and the Reynolds' number highlights the relative importance of viscous action within the flow field.

Using the fluid properties, such as velocity, density, and viscosity, and a characteristic length in the flow field, we can obtain expressions for the inertial and viscous forces. The ratio of inertial to viscous forces gives the dimensionless Reynolds number (Rouse 1946; Flammer et al. 1982; Vogel 1994). The ratio of the fluid dynamic viscosity, $\mu$, to its density, $\rho$, is often referred to as the kinematic viscosity, $\nu=\mu / \rho$, in the widely used form of the Reynolds number:

$$
\mathrm{Re}=\mathrm{L} \cdot \mathrm{U} / \mathrm{V}
$$


where $\mathrm{U}$ is the fluid mean velocity, $v$ is the fluid's kinematic viscosity, and $\mathrm{L}$ is a characteristic length. In the case of a full flowing pipe, L is its diameter, or, for a solid immersed in a fluid, $\mathrm{L}$ is the characteristic length taken to be the greatest length of that solid in the flow direction.

Because Reynolds numbers are proportional to a product of length and velocity within the flow field, their values can range widely in nature. The Reynolds number of a whale swimming at $10 \mathrm{~m} / \mathrm{s}$ is 14 orders of magnitude greater than that of a bacterium swimming at $0.01 \mathrm{~mm} / \mathrm{s}$ (Vogel 1994). The Reynolds number is used as a parameter to describe the laminar versus turbulent nature of a flow. At a Reynolds number of about 1,500 or less, the flow tends to be laminar. Above this value, flow becomes turbulent. A discussion of the nature of turbulence in different parts of the turbine system is provided in Section 3.

\section{Turbulence Intensity}

The pattern of turbulence within a turbulent flow field continuously changes with time (Rouse 1946). Therefore, in order to describe the turbulence in that flow field a continuous record of the instantaneous velocities at the point of interest must be kept; that is essential to perform the necessary statistical analyses. Using the instantaneous velocities turbulence can be described by a measure called turbulence intensity (Gordon et al. 1992).

The local velocity in a turbulent region is composed of a temporal mean value plus a component that represents the turbulent fluctuation about the mean. The turbulence intensity is a measure of the magnitude of the turbulent fluctuations about the mean. When a series of instantaneous velocity measurements are made at a point, the turbulence intensity at that point can be expressed as the root mean square of these measured values.

$$
\text { Turbulence Intensity } \left.=\left[\sum\left(\mathrm{v}_{\mathrm{i}}-\mathrm{v}_{\mathrm{ave}}\right)^{2} \cdot \mathrm{n}^{-1}\right)\right]^{-2}
$$

where $\mathrm{v}_{\mathrm{i}}$ is the instantaneous velocity measurement, $\mathrm{v}_{\mathrm{ave}}$ is the mean velocity of the flow, and $\mathrm{n}$ is the number of instantaneous velocity measurements. Eq. 5 yields a value for turbulence that is expressed in terms of velocity units, e.g., $\mathrm{m} / \mathrm{s}$. This formulation has been reported in studies by Pavlov and Tyuryukov (1993) and Skorobogatov et al. (1996). 
An alternative, but similar, expression of turbulence intensity is found by dividing the standard deviation of the velocity $(\sigma)$ by the mean velocity:

$$
\mathrm{K}_{\mathrm{t}}=\sigma / \mathrm{v}_{\mathrm{ave}}
$$

This dimensionless ratio is an expression of the relative intensity of turbulence. It has been used, for example, by Lacoursiere and Craig (1990) and a series of Russian papers (Pavlov et al. 1982; Pavlov et al. 1994; Lupandin and Pavlov 1996). When multiplied by $100, \mathrm{~K}_{\mathrm{t}}$ is reported as a percentage.

\section{$\underline{\text { Turbulence Scale }}$}

The size of the turbulent fluctuations, i.e. turbulence scale, is also an important consideration (Nowell and Jumars 1984; Peters and Redondo 1997). Globally, turbulence of biological interest can occur in scales as large as $10^{4} \mathrm{~m}$ or more in the ocean down to microscopic scales affecting the movements and feeding of individual planktonic organisms. Turbulence exists at a wide variety of scales in a river, from the swirling motion created when a salmon scoops out a redd (scales smaller than the size of the fish) to large pulses of flow in a river (scales much larger than a fish). Similarly, within a hydropower turbine turbulence occurs at different scales (Figure 2). Smaller-scale turbulence, which occurs throughout turbine passage, can distort and compress portions of the fish's body. Largerscale turbulence may be most pronounced in the draft tube and tailrace, where water flow is decelerating, expanding into a larger passage, and has a swirl imparted on it by the turbine runner. Fixed structures in the draft tube (walls and support piers) may cause secondary flows, i.e., flows moving in opposite directions from the main flow moving out of the draft tube and into the tailrace. Similarly, the configuration of the tailrace can also cause backflows ("tailrace roll") that impede the downstream movement of turbine-passed fish. These chaotic flow conditions (small-scale turbulence, larger-scale flow pulses, vortices, and secondary flows) will distort and spin the fish, and at the least may cause disorientation. It has been suggested that this turbulence-caused disorientation, while perhaps not injuring the fish directly, may leave turbine-passed fish more susceptible to predators in the tailrace. 


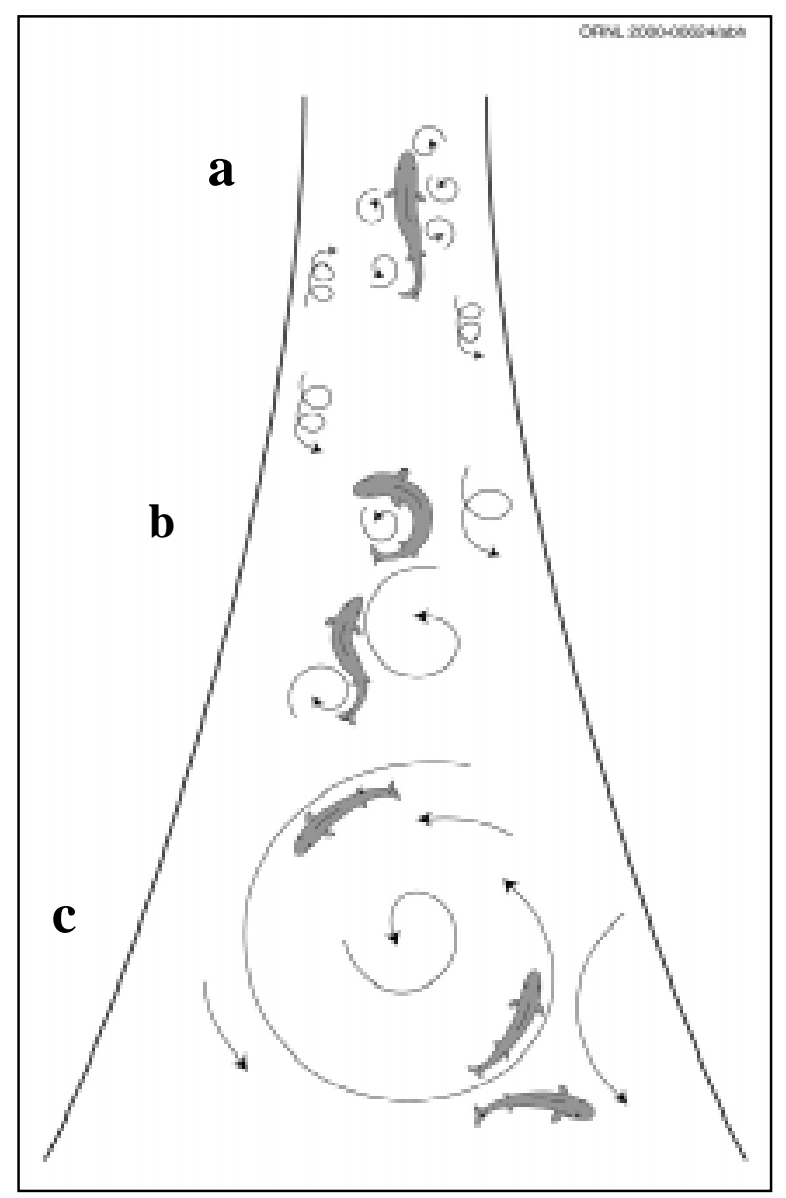

Figure 2. Turbulence scales compared to the size of a fish.

Shear force, shear stress, and turbulence are inextricably linked. For any but the smallest pipes and lowest velocities (in which laminar flows occur), shear stress will cause turbulent eddies. Similarly, turbulent flows, by definition, will create shear forces and shear stress, because parcels of water that are moving in different directions and with different velocities will interact.

In terms of adverse effects on fish there are areas within a turbine in which either shear stress or turbulence predominate. Near a solid-liquid boundary (for example, the runner blade or turbine wall), water velocity decreases very rapidly from the mean velocity of the bulk flow, say 
$15 \mathrm{~m} / \mathrm{s}$, to the non-slip velocity of zero at the solid surface. Some of the energy associated with the large shear stress in this boundary layer is shed as turbulent vortices, but the damage to the fish caught in the boundary layer is caused less by chaotic motions of water particles (turbulence) than by the fact that a portion of its body is proceeding downstream at a different velocity than another portion, leading to distension, compression, bending, torsion, and localized damage. Turbulence is certainly present in the boundary layer, but its adverse effects are overshadowed by the high values of shear stress (Figure $2 \mathrm{a}$ and $2 \mathrm{~b}$ ).

Elsewhere in the turbine system, larger-scale turbulence may overshadow the effects of localized shear stress. In the draft tube outlet and tailrace, where flow is expanding and slowing, velocity differentials are lower compared to those associated with boundary layers within the turbine. Consequently, the shear stresses will be lower as well and are less likely to exert forces great enough to damage fish. In these areas, however, turbulence may be quite high and of a scale larger than that of the fish. In that case, the motion of the fish's body will also be chaotic, like the water surrounding it. Turbulence scale is important because the forces associated with tiny turbulent eddies will cause localized damage (bruises, scale loss) (Figure 2a). Turbulence at a larger scale, e.g., several times the size of the fish, will agitate and spin the fish (Figure 2c). It is believed that residence in an area of large-scale turbulence for enough time will cause the fish to become disoriented, lose equilibrium, have a reduced swimming capacity, and potentially become more susceptible to predators.

From these considerations, it can be seen that experiments designed to measure the biological effects of turbulence must take into account not only the intensity of turbulence, but also the scale. Small-scale, high-intensity turbulent vortices may bruise or descale the fish, but are not of sufficient size to spin the fish and cause disorientation. Turbulence scales at about the same length (L) of the fish will tend to bend or twist the fish's body, which may lead to disorientation but may also cause physical injury (creases and internal damage). Scales of turbulence several times larger than the fish, say $5 \mathrm{~L}$ or $10 \mathrm{~L}$, will transport the fish in random (chaotic) motions, possibly leading to disorientation, loss of equilibrium, and diminished swimming capacity. Our experiments are intended to create an environment in which shear stresses and turbulence are non-damaging, but turbulence intensities and scales are such that 
indirect effects (e.g. disorientation) may occur. The forces associated with smaller scale turbulence will compress a portion of the fish's body, causing direct damage. Larger scale turbulence (larger than L) will cause rotation or some form of translational movement; like the flow itself, the fish's movement will be chaotic in terms of direction and velocity. 


\section{Shear and Turbulence in the Hydropower System}

\section{$\underline{\text { Shear Stress and Turbulence in Rivers }}$}

Levels of shear associated with average flows in natural streams are generally small (Table 1). For example, many stream salmonids inhabit low velocity resting positions from which they make short forays into adjacent faster water to feed on drifting invertebrates. Hayes and Jowett (1994) measured the velocity differences encountered by large brown trout in these normal feeding forays and estimated rate of strain exposures no greater than 5.0 $\mathrm{m} / \mathrm{s} / \mathrm{m}$. Velocity changes experienced by 15 to $30-\mathrm{cm}$-long brook trout feeding in a Michigan stream resulted in strain rates of $0.6 \mathrm{~m} / \mathrm{s} / \mathrm{m}$ or less (Fausch and White 1981). In relatively non-turbulent flows, these values would produce shear stresses of less than $1 \mathrm{~N} / \mathrm{m}^{2}$. Lancaster and Hildrew (1993) measured near-bed shear stresses in small streams; shear stresses were less than $1 \mathrm{~N} / \mathrm{m}^{2}$ at moderate discharges and less than $7 \mathrm{~N} / \mathrm{m}^{2}$ at high discharges. Statzner and Müller (1989) reported 90 measurements of shear stress values at the bottoms of 3 streams. Estimates of shear stress were generally less than $200 \mathrm{~N} / \mathrm{m}^{2}$; most data points were less than $30 \mathrm{~N} / \mathrm{m}^{2}$.

\begin{tabular}{|c|c|c|}
\hline Environment & Shear stress $\left(\mathrm{N} / \mathrm{m}^{2}\right)$ & Reference \\
\hline $\begin{array}{l}\text { Water column in a trout stream, } \\
\text { average flow }\end{array}$ & $<1.0$ & Fausch and White (1981) \\
\hline Small streams, near bed & $<1-7$ & $\begin{array}{l}\text { Lancaster and Hildrew } \\
\text { (1993) }\end{array}$ \\
\hline $\begin{array}{l}\text { Medium-sized streams, near bed } \\
\text { (90 measurements) }\end{array}$ & $\begin{array}{c}\text { most }<30 \text {, but some } \\
>200\end{array}$ & Statzner and Müller (1989) \\
\hline Flash floods, small basins & $61-2600$ & Costa (1987) \\
\hline Floods, large rivers & $6-10$ & Costa (1987) \\
\hline Bulb turbine draft tube & $500-5,421$ & McEwen and Scobie (1992) \\
\hline Near ships' hulls and wakes & $7.6-40.4$ & Morgan et al. (1976) \\
\hline Near barge propeller & $\geq 5,000$ & Killgore et al. (1987) \\
\hline
\end{tabular}


On the other hand, Costa (1987) calculated the shear stresses associated with maximum rainfall-runoff (flash) floods in 11 small basins in the United States. Mean shear stress values ranged from $61 \mathrm{~N} / \mathrm{m}^{2}$ to $858 \mathrm{~N} / \mathrm{m}^{2}$. He also alluded to unpublished shear stress estimates from four other flash floods in small basins that ranged from 1500 to $2600 \mathrm{~N} / \mathrm{m}^{2}$. By comparison, large rivers, such as the Mississippi and Amazon, produce shear stresses of 6 to $10 \mathrm{~N} / \mathrm{m}^{2}$ in flood. Costa (1987) noted that shear stresses are often higher in small basins than in large basins because shear stresses depend not only on discharge but also on hydraulic radius, energy slope, and mean velocity.

It is well known that fish sense and respond to shear stress and turbulence in natural waters. Fish can sense variations in pressure and water velocity on the body surface, especially by means of their lateral line and inner ear (e.g., review by Dijkgraaf 1963). However, what is less well understood are the patterns (if any) of response to these stimuli.

Much of the Russian literature has been focused on the ability of non-migratory fish to maintain position in low velocity, moderately turbulent flows, rather the effects of high, potentially damaging levels of turbulence. For example, Pavlov et al. (1982; 1994) found that increasing the turbulence intensity decreased the fish's critical velocity, i.e., the maximum velocity at which a fish can sustain itself in a stream. They concluded that energy expenditures will be greater for fish attempting to maintain position in streams with turbulent flows because such streams possess more kinetic energy. Surprisingly, Lupandin and Pavlov (1996) found that starved fish tended to select turbulent flows over non-turbulent flows (both water velocities and turbulence were low), possibly because of increased feeding opportunities. Non-migratory fish chose different levels of turbulence, depending on species (rheophilic vs. limnophic groups) and also previous experience (Skorobogatov et al. 1996). When given a choice, fish that inhabit rivers (e.g., gudgeon and grayling) selected water flows with relatively strong turbulence whereas lake-dwelling fish (e.g., crucian carp) preferred low turbulence. 
Pavlov and Tyuryukov (1993) compared the reactions to water currents of dace that were intact or had their lateral line or inner ear disabled. Fish whose lateral lines were disabled by means of a topically applied anaesthetic were still able to maintain proper orientation in both laminar and turbulent flows, but may have had a reduced ability to detect irregularities in the velocity field and to avoid obstacles. On the other hand, compared to unstressed fish, dace that had their inner ear disrupted by centrifugation (10-minute period of swirling flow) were unable to maintain normal orientation in turbulent flows and avoid obstacles. Both of these effects, i.e., the disorientation arising from exposure to swirling flows and the diminished ability to sense and avoid objects in the water, could be expected to increase the fish's susceptibility to predators.

Coutant and Whitney (2000) suggested that turbulence in rivers is used by anadromous fish to speed downstream migration. They believe that migrating juvenile salmon may seek out features of unsteady flow (e.g., turbulent bursts, vortices, and waves) in rivers to find regions of higher velocity than that of the bulk flow. Such features of turbulence as vorticity cannot be measured directly, but must be derived from integrating measurements of velocity at multiple points; Hanke et al. (2000) suggested that the fish's lateral line could serve this purpose. Although the response of juvenile salmonids to natural turbulence has not been extensively studied, Coutant (1998) pointed out that anadromous fish evolved in turbulent rivers, and it would be surprising if they did not take advantage of opportunities to utilize the kinetic energy from turbulence to reduce the metabolic energy needed for swimming. If true, this idea would suggest that there are optimal levels of turbulence for migrating salmonids. If turbulence is too high (as within a turbine draft tube, tailrace, or spillway), it could damage or disorient the juvenile fish. If it is too low (as within a stagnant reservoir), missing are not only the downstream guidance cues and transport function associated with the bulk flow, but also the ability to capitalize on energy associated with large scale, low intensity turbulence.

\section{$\underline{\text { Shear Stress and Turbulence Associated with Ships }}$}

Large vessels, such as commercial barges, can increase shear stress and turbulence in rivers. Mazumder et al. (1993) measured variations in longitudinal, lateral, and vertical water velocities in the Illinois River, both under natural conditions and in response to passing 
barges. The movement of a barge in a restricted channel displaces water, creates surge waves in front of the bow, and generates turbulence (both from water displacement by the hull and action of the propeller). They found that the barge generated larger eddies and more turbulent transverse shear than the natural flows of the river. Maximum values of shear stress from barge passage occurred near the shore, and decreased to near zero in the central zone between the shore and the barge.

In order to assess the effects of shipping on fish eggs and larvae in the Chesapeake and Delaware Canal, Morgan et al. (1976) used rotating concentric cylinders to create shear zones in 30.5-cm-diameter chambers. Striped bass and white perch eggs and larvae were introduced into the layer of water between the cylinders, and consequently exposed to calculated shear stresses ranging from 7.6 to $40.4 \mathrm{~N} / \mathrm{m}^{2}$ for periods of 1 to 20 minutes. Both eggs and larvae were sensitive to these low levels of shear stress. For example, shear stresses of $35 \mathrm{~N} / \mathrm{m}^{2}$ killed an average of 38 percent of the white perch larvae in 1 minute, 52 percent in 2 minutes, and 75 percent after 4 minutes exposure. The authors developed a set of regression equations, which related the amount of shear stress to expected mortality among these fish early life stages. They concluded that shear forces generated by the hull of a large vessel would be unlikely to kill fish eggs and larvae over a brief exposure time. They did not attempt to estimate shear forces and turbulence associated with a ship's propeller.

Maynord (2000) estimated that shear stress associated with the hull of a high-speed, fivebarge-long commercial tow on the Upper Mississippi-Illinois Waterway System (UMRIWWS) would be greater than 250 dynes $/ \mathrm{cm}^{2}$ in only 5 percent of the water mass beneath the tow. Shear stress would be greater than 135 dynes $/ \mathrm{cm}^{2}$ in 50 percent of the region beneath the tow. Vessel passage times (= exposure times for fish) would be around 1-2 minutes. Applying the bioassay data from Morgan et al. (1976), he estimated that hull shear (not including that caused by the propellers) associated with a typical UMR-IWWS tow could cause an average of 9 percent mortality among fish eggs and larvae.

Killgore et al. (1987) examined the effects of turbulence on survival of paddlefish yolksac larvae in the laboratory. Paddlefish larvae were placed in circular containers and exposed to differing frequencies and intensities of turbulence created by water jets. Turbulence in the 
laboratory chambers was expressed in terms of both water velocities $(\mathrm{cm} / \mathrm{s})$ and pressures $\left(\right.$ dynes $\left./ \mathrm{cm}^{2}\right)$. The investigators found that turbulence intensity was more lethal than frequency of disturbance. Low turbulence (1,774-1,902 dynes $/ \mathrm{cm}^{2} ; 177-190 \mathrm{~N} / \mathrm{m}^{2} ; 21.5-22.8$ $\mathrm{cm} / \mathrm{s})$ caused 3 and 13 percent short-term mortality, whereas high turbulence (6,219-6,421 dynes $/ \mathrm{cm}^{2} ; 622-642 \mathrm{~N} / \mathrm{m}^{2} ; 56.5-59.3 \mathrm{~cm} / \mathrm{s}$ ) resulted in 87 and 80 percent short-term mortality. Longer-term direct mortality, indirect mortality, and physiological stress were not examined. Based on these laboratory studies and field measurements of pressures near commercial barges (which sometimes exceeded 50,000 dynes $/ \mathrm{cm}^{2}\left[5,000 \mathrm{~N} / \mathrm{m}^{2}\right]$ near the propellers), Killgore et al. (1987) suggested that turbulence generated in the immediate vicinity of commercial vessels could cause mortality among paddlefish larvae.

Recognizing that shear stresses and turbulence caused by tow boat propellers are much larger than those induced by the hull, Killgore et al. (2000) exposed fish eggs and larvae to a scale model propeller in a recirculating water channel. In their experiment, observed mortalities resulted from a combination of fluid stresses (shear and turbulence) and propeller blade impact. Sensitivity varied with species and life stage, but was directly related to the calculated magnitude of shear stress. Significant mortalities were observed for most species at the highest shear stress levels; for example, 83 percent of lake sturgeon larvae were killed by exposure to 4,743 dynes $/ \mathrm{cm}^{2}$. High shear stresses can occur in the zone between the propeller blades, the zone downstream of individual blades, near the hub, and within and around the perimeter of the propeller-induced jet. The authors concluded that fluid stresses in the zone of influence of tow boat propellers can be a major source of mortality for larval fishes and a relatively minor source of mortality to fish eggs and juveniles.

\section{Shear Stress and Turbulence at Hydroelectric Power Plants}

McEwen and Scobie (1992) estimated that shear stresses within a reference bulb turbine could average over $500 \mathrm{~N} / \mathrm{m}^{2}$; maximum values were estimated to be 3,740 and $5,421 \mathrm{~N} / \mathrm{m}^{2}$ for "on-design" and "off-design" conditions, respectively. On the basis of these calculations, Turnpenny et al. (1992) designed a laboratory apparatus that could expose fish to localized shear stresses of this magnitude. They introduced fish into a high-velocity water jet submerged in a tank of static water, then examined the fish for injuries and long-term 
mortality. Jet velocities tested ranged from 5 to over $21 \mathrm{~m} / \mathrm{s}$, resulting in maximum shear stresses ranging from 206 to $3,410 \mathrm{~N} / \mathrm{m}^{2}$.

Salmonids (Atlantic salmon, rainbow trout, and brown trout) tested at the lowest shear stresses (maximum values of 206 and $774 \mathrm{~N} / \mathrm{m}^{2}$ ) experienced little scale loss, no loss of mucous coating, no other apparent injuries, and no mortality up to 7 days after the single exposure. Greater jet velocities and shear stresses resulted in more injuries and lower longterm survival (Turnpenny et al. 1992). For example, at the highest shear stresses tested (maximum value near the jet of $3,410 \mathrm{~N} / \mathrm{m}^{2}$ ), localized loss of mucous cover and some eye damage (corneal rupture; pop-eye; hemorrhaging in the eye) was noted; survival was around 90 percent 7 days after the test. Fish that died after exposure to the higher shear stress levels were heavily coated with fungus, probably because the loss of mucous increased their susceptibility to fungal infections.

Clupeids (shad, herring) were much more susceptible to shear stresses in the experiments of Turnpenny et al. (1992). All fish tested in the apparatus, even at the lowest maximum shear stress of $206 \mathrm{~N} / \mathrm{m}^{2}$, died within 1 hour. Many clupeids suffered eye damage, eye loss, torn and bleeding gills, and substantial loss of scales and mucous layer. At the other end of the scale, eels suffered no evident damage, other than some loss of mucous coating, and no 7day mortality even at the highest shear stress levels tested.

Turnpenny et al. (1992) observed visible creases on the body surfaces of some fish entrained in the turbulent jet, which led to crushing of internal organs and internal hemorrhaging. Eye damage (corneal rupture, pop-eye, or red-eye) or eye removal were also common injuries among the fish exposed to these localized shear stresses. Finally, osmotic imbalance caused by loss of much of the mucous layer and underlying scales is believed to be the reason for the sensitivity of clupeids to even low levels of shear. Eels, which have substantial mucous layers, were not injured by high shear stresses.

Groves (1972) exposed juvenile salmon (total lengths ranging from 3.5 to $13.5 \mathrm{~cm}$ ) to a water jet submerged in a tank of static water. In his experimental protocol the jet was brought to full speed (mean calculated velocities ranged from 9 to $37 \mathrm{~m} / \mathrm{s}$ ) and the fish were immediately introduced to the tank near the nozzle. Each test lasted only for the time needed 
to introduce the fish, usually less than a second. Thus, exposure to shear in this experiment was a brief, one-time exposure to high velocity water at the edge of the jet. The actual velocities and shear stresses experienced by fish were not measured. Some of the tests included high-speed photography to track the fishes' movements, and all tests examined the resultant types of injuries and mortality. Juvenile salmon were unaffected by exposure to the lowest velocity jet tested, $9 \mathrm{~m} / \mathrm{s}$. As jet velocities increased the rates of disorientation, visible injury, and mortality also increased (Groves 1972). Fish disabled (disoriented) but without visible injury usually regained normal capacities in 5 to 30 minutes. Visible injuries were mostly in the head region and included bulged or missing eyes, broken and ripped gill covers, and torn gills. Whereas visible injuries and mortalities were zero at $9 \mathrm{~m} / \mathrm{s}$, velocities of 15 $\mathrm{m} / \mathrm{s}$ caused injuries in 2 to 59 percent of the fish in the test batches. At any given jet velocity, injury rates were inversely related to the size of the fish, i.e., 3-cm salmon were more often injured than 13-cm-long salmon.

Injury from the water jet was related to the part of the fish contacted and to the position of the fish relative to the jet flow direction at the time of contact (Groves 1972). Greatest injuries occurred when the jet contacted the head region and was moving from the rear towards the head of the fish. Larger fish were less affected if the jet initially contacted some other portion of the body than the head, or if the fish was facing into the jet stream. On the other hand, smaller fish were damaged irrespective of their orientation. Groves attributed this size-related difference in injury rates to the proportion of the fish's surface area struck by the jet. The jet struck a relatively larger portion of a small salmon's body, and at the higher velocities some were literally torn apart. Larger fish had a proportionately small portion of their bodies contacted by the margin of the jet, so injuries tended to be more frequent when initial contact was with more protruding or less rigidly attached parts of their head region, such as the gill structures and eyes.

Heisey et al. (2000) catalogued the injuries they observed on fish that had passed through hydroelectric turbines in the Pacific Northwest. In 10 studies, a loss of equilibrium was noted in 0.4 to 4.1 percent of the turbine-passed fish (depending on project), which they attributed to the effects of turbulence. Commonly, between 1 and 2 percent of the mid-blade-passed 
fish experienced loss of equilibrium. In the most recent study of turbine passage survival at Bonneville Dam First Powerhouse, 1.2 percent of the turbine-passed fish exhibited loss of equilibrium (Normandeau Associates et al. 2000). Passage route (i.e, whether the fish passed through the runner near the hub, near mid-blade, or near the blade tip) did not appear to affect the incidence of equilibrium loss.

Davidson (2000) described the nature of turbulence that is believed to occur within different parts of a hydroelectric turbine. His descriptions related to a typical Kaplan turbine installation on the Columbia River, but general characteristics apply to a large number of hydropower plants. The eight "Hazard Passage Zones," starting at the turbine intake and ending in the draft tube outlet (Figure 3), are:

Zone 8 - upstream of the submerged intake (fish) screens. The water has low velocities (5 to 7 fps), low turbulence, and low potential for fish injury. Also, the horizontal components of the trash rack (upstream from the fish screens) can cause large turbulent wakes that propagate as much as 30 feet downstream and can affect velocity distributions.

Zone 1 - immediately downstream of the fish screens. The zone is characterized by an uneven velocity distribution (caused, in part, by the screens), high turbulence in the wake of the screen, and moderate velocity shear.

Zone 2 - upstream from and within the scroll case. Within the scroll case, velocities range from 8 to $15 \mathrm{fps}$, and flow is turbulent if fish screens are in place. Immediately upstream from the scroll case large, recirculating rollers may be created that cause an interchange of flow between bays and my create holding areas for fish.

Zone 3 - wicket gates and stay vanes. Water velocities accelerate rapidly in this region from 9 to 30 fps. Shear stress can be very high, especially near surfaces.

Zone 4 - runner. Very high velocities (and shear) occur near surfaces. Turbulence associated with the trailing edge of the runner and hub and blade tip gaps may be very high. Turbulent vortices are shed from the hub.

Zone 5 - downstream of the runner to the draft tube. Water velocities decrease in this expanding area from about $40 \mathrm{fps}$ to $20 \mathrm{fps}$. All fish pass through this area of potentially high shear and high intensity turbulent vortices coming off trailing edges of the runner, gaps, and the runner hub.

Zone 6 - draft tube. The cross-sectional area continues to expand in this zone, resulting in decelerating flows, high turbulence, and very non-uniform velocity distributions within each barrel (section) of the draft tube. Adding to the chaotic nature of the 
flow, larger draft tubes have support piers that split the swirling flow (often unevenly) leaving the runner, causing turbulence and secondary (reverse) flows.

Zone 7 - draft tube outlet to tailrace. With increasing cross-sectional area, flows decelerate to an average of about $7 \mathrm{fps}$. This area is characterized by very non-uniform velocity distributions (in terms of both magnitude and direction of flow), largescale turbulence, and potentially formation of a backroll that can trap fish in the tailrace. Hydraulic conditions here are expected to disorient, rather than directly injure, fish.

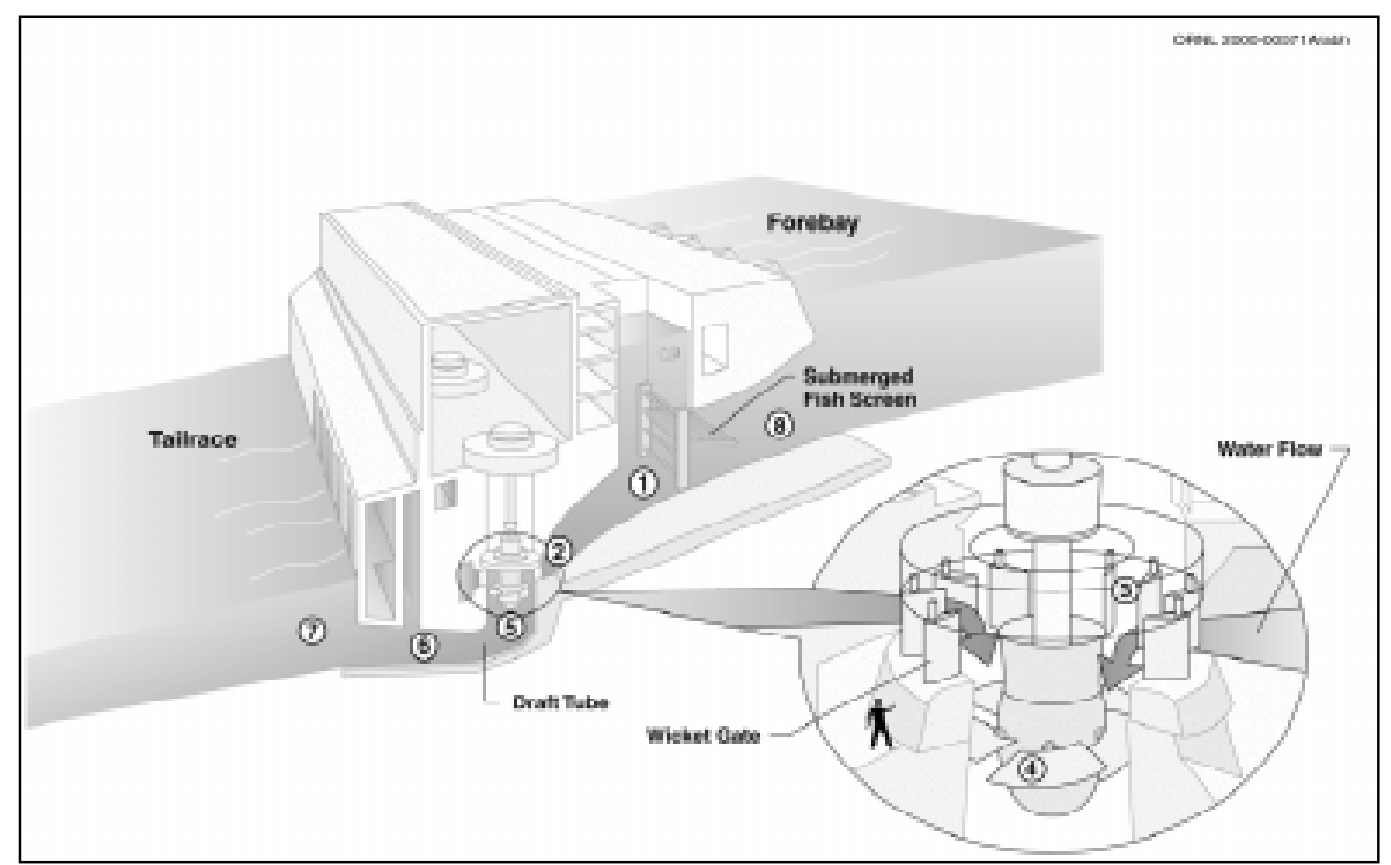

Figure 3. Eight Hazard Passage Zones associated with passage through a hydroelectric turbine. Source: Davidson (2000).

Much of the interest in studying the adverse biological effects of turbulence is focused on Zones 6 and 7, where turbulence is high and dominates other fish injury mechanisms. Wittinger (2000) pointed out that draft tubes are designed to handle the maximum (nameplate) flow through a turbine. Unlike Kaplan turbines, in which wicket gate positions and blade angles are coordinated in order to operate efficiently 
under a range of hydraulic heads and flows, the geometry of draft tubes does not change with changes in flow. Compared with adjustable blade turbines, then, under most operating conditions, flows are transported through the draft tube inefficiently. These inefficiencies are dissipated as turbulence; in the upper draft tube (Zone 6), the tangential (sideways) velocity, which is proportional to turbulence, can be 50 percent of the axial (downstream) velocity (Rod Wittinger, personal communication). The energies associated with these turbulent flows can be expected to impact entrained fish.

There are numerous draft tube designs, ranging from a straight conical diffuser to configurations with bends and bifurcations (Gulliver and Arndt 1991). Diffuser designs are often tradeoffs that seek to minimize construction cost and effort while avoiding flow separations, unstable flow, excessive swirl, and vibrations that can affect turbine efficiency.

Water discharged from dams via spillways can reach velocities of tens of meters per second, which can create high values of shear stress and turbulence, especially near solid surfaces. At high velocities (12 to $15 \mathrm{~m} / \mathrm{s}$ or more), surface irregularities can cause flow separations that are sufficient to lower water pressure below the local vapor pressure and cause cavitation (Chanson 1989). These extreme flow separations can occur within flowexpansion tunnels (such as draft tubes), along the floor of the spillway, near baffle blocks and other structures in stilling basins, and in association with vortices near gates and gate slots (Hamilton 1983). Flow separations that can cause cavitation might also be expected to exert damaging shear stress on fish being transported in these flows. The effects of spillway discharges on fish have not yet been rigorously examined. However, in 38 tests done at 6 hydroelectric projects in the Columbia River basin, Heisey et al. (2000) observed visible injuries among 0 to 7.0 percent of spilled/bypassed fish. No loss of equilibrium was seen in 23 of the 38 tests, but in the other 15 tests loss of equilibrium ranged from 0.1 to 4.7 percent among spilled fish. 


\section{Experimental Studies Needed to Resolve the Turbulence Issue at Hydroelectric Power}

Plants

\section{Experimental Apparatus}

The studies described in the previous section provide a very preliminary look at the potential effects of shear stress and turbulence. We know from field observations that disorientation occurs in turbine-passed and spillway-passed fish, but we don't yet know its biological significance. A full understanding of the biological effects of turbulence at hydropower plants will require a combination of three approaches: laboratory experiments, computer modeling, and field studies. Laboratory studies are needed to establish the levels of turbulence that are harmful to fish. Controlled, replicable laboratory experiments can be used to develop biological criteria, i.e., the levels below which turbulence associated with turbine and spillway passage will not cause either direct or indirect mortality. Computational modeling can be used to extend the results of laboratory experiments to other, unstudied conditions. For example, velocity measurements made in the field can be used in a computational fluid dynamics (CFD) model to predict the location and size of regions inside a turbine that were found (in laboratory studies) to have damaging levels of turbulence. Once these CFD models have been calibrated, the biological effects of changes in turbine design and operation can be explored. Finally, field studies are needed to verify the predictions of the laboratory and computational studies.

Unfortunately, none of the above-mentioned methodologies has yet been used to describe the flow conditions within a tailwater of a turbine just downstream of the draft tube exit. In order to determine the appropriate tailwater conditions to test in our experimental apparatus, we contacted leading experts in the fields of hydraulics associated with hydroelectric power plants. These experts include university professors, government employees, and industry representatives. A short list of these includes:

Professor Fotis Sotiropoulos, Georgia Institute of Technology Professor Thanos Papanicolaou, Washington State University Professor John Gulliver, University of Minnesota

Mr. Patrick March, Tennessee Valley Authority

Mr. Richard Fisher, Voith Siemens Hydro Power Generation 
Mr. Rod Wittinger, U.S. Army Corps of Engineers

Mr. Richard Fisher, Voith-Siemens Hydro

Professor Larry Weber, Iowa State University

They informed us that to date such turbulence information is available only for the turbine system components found upstream of the tailrace, such as draft tube, scroll case, penstock, etc. Hydropower turbine tailrace field conditions are extremely chaotic and may be dangerous for researchers to study. In addition, documenting tailrace turbulence intensities and scale in the field would require a special instrument to be deployed at various locations, following a grid system, for adequate periods of time at each location.

Turbulence intensity at a point in the flow field is a measure obtained from statistical analysis performed on the instantaneous velocity measurements taken continuously for a period of time at that point (Rouse 1946). Because the environment in the tailrace is chaotic and unpredictable it would be very difficult to install a velocity meter and fix its probe at a point in the flow field and record instantaneous velocities. Recent developments of Acoustic Doppler Current Profiler (ADCP) meters may facilitate documentation of turbulence intensities in a tailrace. These velocity meters are typically used to document average current velocities in rivers and oceans successfully. They can be deployed from a moving boat (or a platform) and are able to provide velocity measurements at points of various depths instantaneously, but not instantaneous velocities over a period of time at the same point.

The absence of instantaneous velocity information has made it challenging for us to develop turbulence design criteria for our laboratory apparatus. Therefore, we developed a system that will be capable of providing a wide range of turbulence intensities and scales, a range that we believe will encompass conditions found in hydropower tailwaters. Owing to the present lack of information on tailrace turbulence characteristics, we will construct an apparatus that will be capable of accurately and repeatedly reproducing shear stresses (a closely related hydraulic variable) comparable to those in Table 1.

The "Turbulence Chamber" will basically be a rectangular tank made out of steel members and acrylic sides and bottom (measuring $122 \mathrm{~cm}$ wide x $300 \mathrm{~cm}$ long x $122 \mathrm{~cm}$ deep) with changing flow inlet designs. The schematic diagram in Figure 4 shows the 
chamber with the nozzles option used for inflow. The nozzle sizes and direction of their flow jets are adjustable to accommodate the desired turbulence condition. The nozzle inlet design can accommodate up to 40 nozzles, each up to $19 \mathrm{~mm}$ ( $0.75 \mathrm{in})$ in diameter. Water supply pumps will be capable of providing up to $0.14 \mathrm{~m}^{3} / \mathrm{s}\left(5 \mathrm{ft}^{3} / \mathrm{s}\right)$ to the nozzles and up to 0.22 $\mathrm{m}^{3} / \mathrm{s}\left(8 \mathrm{ft}^{3} / \mathrm{s}\right)$ if the draft tube was used. The screen reduces refuge areas within the chamber and provides protection for fish against corners and exit conditions. The screen can be installed at varying angles to the vertical; which will be determined upon understanding the performance of the apparatus and fish behavior.

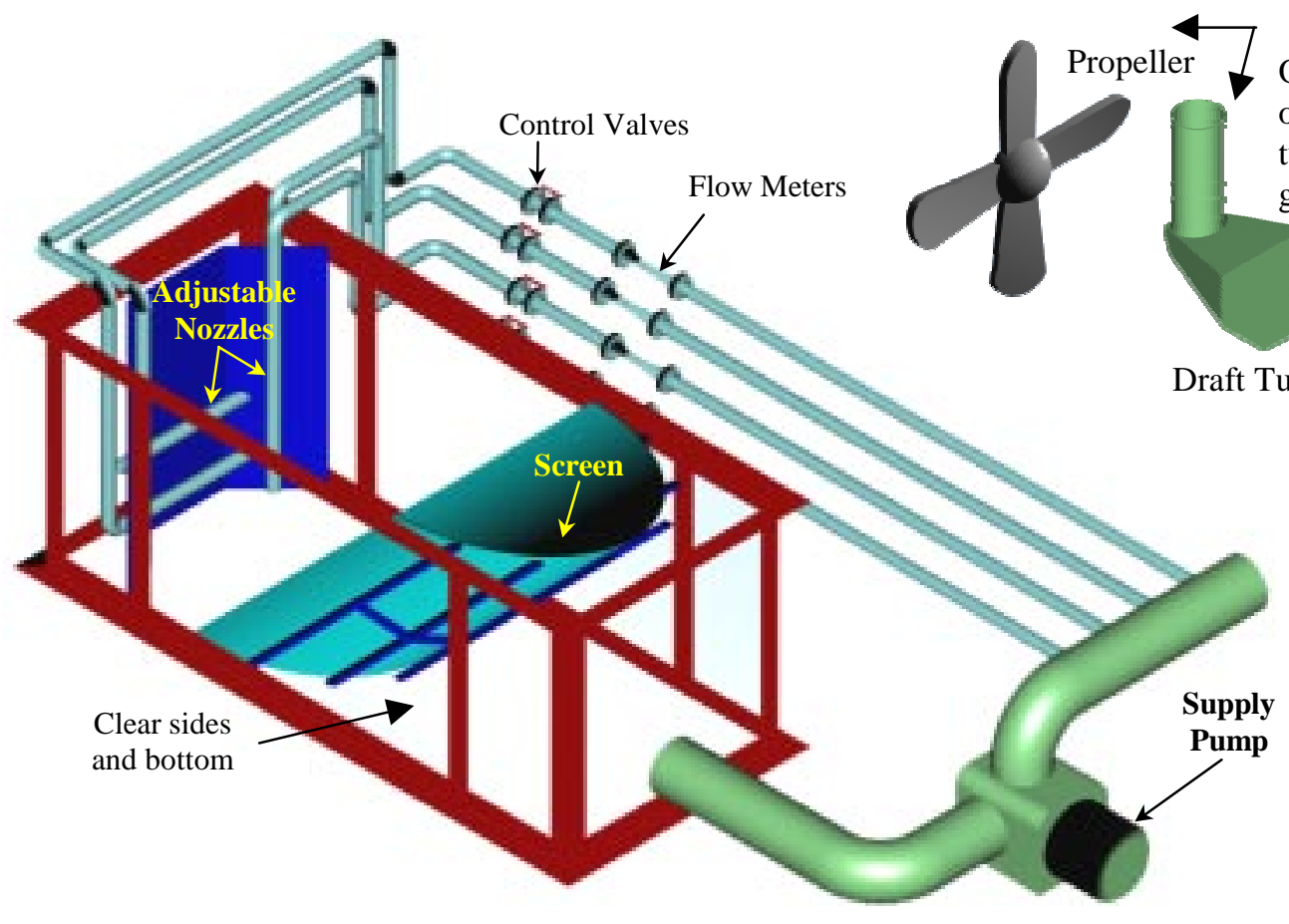

Figure 4. Schematic of the proposed turbulence chamber with the nozzles inlet option in place. The draft tube and propeller inserts can be used as other flow inlets.

Instantaneous velocity measurements will be recorded at various test conditions inside the chamber. An Acoustic Doppler Velocimeter (ADV, Model ADV-Lab by Sontek) will be used to record the three-dimensional instantaneous velocities. These will be taken at a predetermined grid system covering the entire chamber. Inflow and outflow will be documented with the aid of 
accurately calibrated Venturi flow meters ( $0.25 \%$ accuracy). This guarantees accuracy and repeatability of hydraulic test conditions with different groups of fish.

During testing periods the fish will be observed and their behavior documented using video cameras. Fish are expected to exhibit behaviors dependent on the test condition while they are within the chamber and they will also be monitored after removal from the tank.

\section{$\underline{\text { Biological Studies }}$}

\section{Treatment and Control Groups}

Biological experiments will be conducted using control and treatment fish. Control individuals/groups are fish that will be exposed to a particular test condition in the chamber for 10 minutes without turbulence. Behavior inside the chamber and afterwards in holding tanks will be monitored and documented. Treatment individuals/groups are fish that will be exposed to the same turbulence condition in the test chamber, also for 10 minutes, as well as the same handling steps as the control fish. Both treatment and control fish will be exposed to the same test chamber with and without turbulence, respectively.

The treatment and control fish will be placed into different tanks and simultaneously exposed, e.g. for a 10- minute period, to the same conditions for behavioral comparisons; for example exposure to predators. Initially, we will use the same number of control and treatment fish, e.g., 10 fish per group. If control mortality is low or zero we will consider cutting back on the number of control fish used.

\section{Definition of Hypotheses}

The aim of this study is to create levels of turbulence that are representative of hydroelectric plant tailraces or draft tubes, then see if there is a biological response. We will attempt to create turbulent conditions that cause no direct injuries or mortality, but may reduce the fish's swimming ability or escape ability.

Examples of the types of null (Ho) hypotheses to be tested are:

Ho: Exposure to an average turbulence intensity and scale for 10 minutes does not cause descaling in American shad juveniles. 
Ho: Exposure to an average turbulence intensity and scale for 10 minutes does not cause increased susceptibility to predation among Atlantic salmon juveniles.

Ho: Compared to controls, exposure to an average turbulence intensity of 25 percent, a mean velocity of $0.25 \mathrm{~m} / \mathrm{s}$, and a turbulence scale of $0.5 \mathrm{~m}$ does not cause increased 48-h mortality among juvenile rainbow trout.

There could be a large number of these testable hypotheses, depending on the number of test conditions we will create, the number of fish species/sizes to be tested, and the number of biological response variables to be measured.

Fish Species, Sizes, and Numbers

The experimental species will include migratory fish or 'good' substitutes. These may include, among others, Atlantic salmon smolts $\underline{\text { Salmo salar }}(13-18 \mathrm{~cm}$, or 5-7 inches), juvenile rainbow trout Oncorhynchus mykiss (8-15 cm, 3-6 inches), and juvenile American shad Alosa sapidissima $(5-8 \mathrm{~cm}, 2-3$ inches $)$. Initially we are planning on using 20 fish per replicate (10 exposed fish +10 controls). We will perform five replicates per test condition (which is a combination of turbulence intensity, scale, and exposure time). In the case of high control survival, we may use fewer controls.

\section{Holding Period and Observations}

We are not expecting serious external or internal injuries from the exposure to the test conditions. Therefore, the fish will be held for a 48-h post-test period to observe any latent effects. Each fish will be examined for external injuries immediately after the 10-minute exposure time. These may include descaling, torn or lost fins, bruises, scrapes, and torn opercula. Also, swimming capability and mortality will be documented at the following intervals: immediately, 30 minutes, $24 \mathrm{hrs}$, and $48 \mathrm{hrs}$. We will note whether fish are disoriented, listing, occupy different levels of the holding tank than controls; or exhibit diminished startle response, increased startle response, diminished maximum swim speed, increased or decreased susceptibility to predation.

Mortality will be tallied at each observation period. External injuries will be enumerated once; before the fish is placed into the post-test holding tank. Measures of swimming ability 
will be done immediately and every 5 minutes for a 30 -minute period. 


\section{Literature Cited}

Chanson, H. 1989. Flow downstream of an aerator - aerator spacing. Journal of Hydraulic Research 27(4):519-536.

Costa, J.E. 1987. Hydraulics and basin morphometry of the largest flash floods in the conterminous United States. Journal of Hydrology 93:313-338.

Coutant, C.C., L.D. Calvin, M.W. Erho, J.A. Lichatowich, W.J. Liss, W.E. McConnaha, P.R. Mundy, J.A. Stanford, R.R. Whitney, R.N. Williams, D.L. Bottom, and C.A. Frissell. 1997. The normative river: An ecological vision for the recovery of the Columbia River salmon. pages 50-59 IN Waterpower 97. Proceedings of the International Conference on Hydropower. D.J. Mahoney (ed.). American Society of Civil Engineers, New York, NY.

Coutant, C.C. 1998. Turbulent attraction flows for juvenile salmonid passage at dams. ORNL/TM-13608. Oak Ridge National Laboratory, Oak Ridge, TN. 28 p.

Coutant, C.C. and R.R. Whitney. 2000. Fish behavior in relation to passage through hydropower turbines: A review. Transactions of the American Fisheries Society 129:351-380.

Davidson, R. 2000. Modeling fish passage through turbines. Proceedings of the Turbine Passage Survival Workshop. June 14-15, 2000. U.S. Army Corps of Engineers, Portland, OR.

Dijkgraaf, S. 1963. The functioning and significance of the lateral-line organs. Biological Reviews 38(1):51-105.

Fausch, K.D. and R.J. White. 1981. Competition between brook trout (Salvelinus fontinalis) and brown trout (Salmo trutta) positions in a Michigan stream. Canadian Journal of Fisheries and Aquatic Sciences 38: 1220-1227.

Flammer, G., R. Jeppson, and H. Keady. 1982. Fundamental Principles and Applications of Fluid Mechanics. Utah State University. 356 p.

Gordon, N.D., T.A. McMahon, and B.L. Finlayson. 1992. Stream hydrology: An introduction for ecologists. John Wiley \& Sons, New York, NY. 526 p.

Groves, A.B. 1972. Effects of hydraulic shearing actions on juvenile salmon (Summary report). Northwest Fisheries Center, National Marine Fisheries Service, Seattle, WA. 7 p.

Gulliver, J.S. and R.E.A. Arndt. (eds.) 1991. Hydropower engineering handbook. McGraw-Hill, Inc. New York, NY.

Hamilton, W.S. 1983. Preventing cavitation damage to hydraulic structures. Part two. Water Power \& Dam Construction. December 1983:48-53.

Hanke, W., C. Brïcker, and H. Bleckmann. 2000. The ageing of the low-frequency water disturbances caused by swimming goldfish and its possible relevance to prey detection. The Journal of Experimental Biology 203:1193-2000. 
Hart, D.D., B.D. Clark, and A. Jasentuliyana. 1996. Fine-scale field measurements of benthic flow environments inhabited by stream invertebrates. Limnology and Oceanography 41(2):297-308.

Hayes, J.W. and I.G. Jowett. 1994. Microhabitat models of large drift-feeding brown trout in three New Zealand rivers. North American Journal of Fisheries Management. 14:710-725.

Heisey, P.G., D. Mathur, J. Fulmer, and S. Adams. 2000. Analysis and interpretation of injuries to turbine passed fish. Proceedings of the Turbine Passage Survival Workshop. June 1415, 2000. U.S. Army Corps of Engineers, Portland, OR.

Killgore, K.J., A.C. Miller, and K.C. Conley. 1987. Effects of turbulence on yolk-sac larvae of paddlefish. Transactions of the American Fisheries Society 116:670-673.

Killgore, K.J., S.T. Maynord, M.D. Chan, and R.P. Morgan II. 2000. Evaluation of propellerinduced mortality on early life stages of selected fish species. ENV Report 30. U.S. Army Corps of Engineers Rock Island, St. Louis, and St. Paul Districts. 15 p.

Lacoursiere, J.O. and D.A. Craig. 1990. A small flume for studying the influence of hydrodynamic factors on benthic invertebrate behaviour. Journal of the North American Benthological Society 9(4):358-367.

Lancaster, J. and A.G. Hildrew. 1993. Characterizing in-stream flow refugia. Canadian Journal of Fisheries and Aquatic Sciences 50:1663-1675.

Lupandin, A.I. and D.S. Pavlov. 1996. The effects of starvation on the reaction of fish to flows with different intensity in turbulence. Journal of Ichthyology 36(5):408-411.

Maynord, S.T. 2000. Concentric cylinder experiments of shear mortality of eggs and larval fish. ENV Report 23. U.S. Army Corps of Engineers Rock Island, St. Louis, and St. Paul Districts. 10 p. + appendix.

Mazumder, B.S., N.G. Bhowmik, and T.W. Soong. 1993. Turbulence and Reynolds stress distribution in a natural river. Report No. 93-R012. U.S. Fish and Wildlife Service, Environmental Management Technical Center, Onalaska, WI. 6 p.

McEwen, D. and G. Scobie. 1992. Estimation of the hydraulic conditions relating to fish passage through turbines. NPC001. National Engineering Laboratory, East Kilbride, Glasgow. $155 \mathrm{p}$.

Miller, D.S. 1990. Internal flow systems - Design and performance prediction. $2^{\text {nd }}$ edition. Gulf Publishing Company. Houston, Texas. 396 p.

Morgan, R.P., II, R.E. Ulanowicz, V.J. Rasin, Jr., L.A. Noe, and G.B. Gray. 1976. Effects of shear on eggs and larvae of striped bass, Morone saxatilis, and white perch, M. americana. Transactions of the American Fisheries Society 105(1):149-154.

Neitzel, D.S., D. Dauble, M. Richmond, and G.F. Cada. 2000a. Developing biological specifications for fish friendly turbines. Proceedings of HydroVision 2000, Charlotte, NC. August 8-11, 2000. 
Neitzel, D.S., M.C. Richmond, D.D. Dauble, R.P. Mueller, R.A. Moursund, C.S. Abernethy, G.R. Guensch, and G.F. Cada. 2000b. Laboratory studies of the effects of shear on fish. Report to the U.S. Dept. of Energy Idaho Operations Office, Idaho Falls, ID. 66 p. + appendices.

Nezu, I. and H. Nakagawa. 1993. Turbulence in open-channel flows. Balkema, Rotterdam, The Netherlands.

Normandeau Associates, Inc., J.R. Skalski, and Mid Columbia Consulting, Inc. 2000. Passage survival and condition of chinook salmon smolts through existing and new Minimum Gap Runner turbines at Bonneville Dam First Powerhouse, Columbia River. July 19, 2000 Draft Report to U.S. Army Corps of Engineers, Portland District, Portland, OR. 20 p. + appendices.

Nowell, A.R.M. and P.A. Jumars. 1984. Flow environments of aquatic benthos. Annual Review of Ecology and Systematics 15:303-328.

Pavlov, D.S., M.A. Skorobogatov, and L.G. Shtaf. 1982. Influence of degree of stream turbulence on the magnitude of the critical current velocity for fish. Doklady Biological Sciences 267:560-562.

Pavlov, D.S. and S.N. Tyuryukov. 1993. The role of lateral-line organs and equilibrium in the behavior and orientation of the dace, Leuciscus leuciscus, in a turbulent flow. Journal of Ichthyology 33(5):45-55.

Pavlov, D.S., A.I. Lupandin, and M.A. Skorobogatov. 1994. Influence of flow turbulence on critical flow velocity for gudgeon (Gobio gobio). Doklady Biological Sciences 336:215217.

Pavlov, D.S., A.I. Lupandin, N.G. Degtyareva, and S.M. Dedov. 1995. Role of turbulence in the distribution of downstream migrating young fishes (early larval stages) in wide and narrow channels. Doklady Biological Sciences 341:211-215.

Rouse, H. 1946. Elementary Mechanics of Fluids. John Wiley \& Sons, New York. 376p.

Peters, F. and J.M. Redondo. 1997. Turbulence generation and measurement: application to studies on plankton. Scientia Marina 61(suppl. 1):205-228.

Skorobogatov, M.A., D.S. Pavlov, and A.I. Lupandin. 1996. Effects of current velocity and turbulence intensity on the distribution of the roach Rutilus rutilus in a water stream. Journal of Ichthyology 36(8):654-658.

Statzner, B., J.A. Gore, and V.H. Resh. 1988. Hydraulic stream ecology: observed patterns and potential applications. Journal of the North American Benthological Society 7(4):307-360.

Statzner, B. and R. Müller. 1989. Standard hemispheres as indicators of flow characteristics in lotic benthos research. Freshwater Biology 21:445-459. 
Turnpenny, A.W.H., M.H. Davis, J.M. Fleming, and J.K. Davies. 1992. Experimental studies relating to the passage of fish and shrimps through tidal power turbines. Marine and Freshwater Biology Unit, National Power, Fawley, Southhampton, Hampshire, England.

Vogel, S. 1988. Life's Devices. The Physical World of Animals and Plants. Princeton University Press, Princeton, NJ. 467 p.

Vogel, S. 1994. Life in moving fluids - The physical biology of flow. Second Edition. Princeton University Press, Princeton, NJ. 352 p.

White, F. 1992. Viscous Fluid Flow. McGraw-Hill, Inc. New York.

Williams, R.N., L.D. Calvin, C.C. Coutant, M.W. Erho, J.A. Lichatowich, W.J. Liss, W.E. McConnaha, P.R. Mundy, J.A. Stanford, R.R. Whitney, D.L. Bottom, and C.A. Frissell. 1996 draft. Return to the river: Restoration of salmonid fishes in the Columbia River ecosystem. Report 96-6, Northwest Power Planning Council, Portland, OR. 